\title{
IDENTIFICAÇÃO DO LAYOUT ADEQUADO EM UMA EMPRESA DE TECNOLOGIA ELETRÔNICA
}

\author{
José Almir de Souza Júniora \\ Mayara Helen Soares de Andrade ${ }^{a}$ \\ ${ }^{a}$ Fotosensores, Fortaleza, Brasil \\ Breno Barros Telles do Carmo ${ }^{b}$ \\ ${ }^{\mathrm{b}}$ Universidade Federal Rural do Semi Árido, UFERSA, Mossoró, Brasil \\ Kamilla Giló Santiago ${ }^{\mathrm{c}}$ \\ Marcos Ronaldo Albertin \\ c Universidade Federal do Ceará, UFC, Fortaleza, Brasil
}

\section{Resumo}

Atualmente, observa-se uma competitividade imposta pela economia globalizada que faz com que as empresas busquem a produção de produtos cada vez melhores e com menor custo. A redução de custos pode advir da localização dos recursos de produção, representando uma vantagem competitiva para as empresas, com a redução de custos de movimentação dentro do sistema produtivo. Assim, o presente artigo tem por objetivo fazer um estudo e mudança de arranjo físico em uma empresa de tecnologia eletrônica. Logo, optouse em trabalhar com dois tipos de layout, o funcional e o celular. No fim, escolheu-se o arranjo funcional, pois como os itens fabricados possuiam processos com necessidades similares, a redução de custos advinda da movimentação foi obtida quando os equipamentos foram localizados próximos um ao outro, beneficiando a utilização dos recursos materiais e transformadores.

Palavras-chave: Layout Celular e Funcional. Competitividade. Redução da Movimentação 


\section{INTRODUÇÃO}

Existem dois grupos de ações que as empresas devem desenvolver para se manterem competitivas: inovação e custo. Na primeira dimensão, inovação de produtos deve ser o foco da organização. Já na segunda, um estudo da localização dos recursos de produção podem representar uma vantagem competitiva para as empresas, com a redução de custos de movimentação dentro do sistema produtivo. Slack et. al. (2002) coloca os desperdícios listados pelo sistema Toyota de Produção. Um deles é chamado de desperdício por transporte. Este tipo de desperdício está associado ao caminho que um produto segue dentro de um sistema produtivo. Logo, esta distância deve ser minimizada para redução deste tipo de desperdício, ao qual está associado um custo.

A organização dos recursos produtivos tem um papel vital dentro das empresas. O objetivo da gestão destes recursos é alinhar os elementos do sistema produtivo de uma forma que garanta um fluxo eficiente do produto pelo processo de produção da empresa (CHASE et al., 2006), minimizando as distâncias percorridas pelos produtos dentro deste sistema.

Albertin (2007) entende que a gestão de recursos produtivos tem por objetivo a eliminação de perdas e a melhoria contínua nos processos produtivos, tornando o processo mais eficiente. Os conceitos de eliminação de perdas e melhorias contínuas estão interligados e significam que nada desnecessário deve ser feito e que melhorias nos processos produtivos é um objetivo constante.

Uma das formas de organizar os recursos produtivos e reduzir os custos de transporte são os modelos de planejamento de leiaute. Lorenzatto e Ribeiro (2007) entendem que o principal motivo para o planejamento do leiaute do setor produtivo é a redução dos custos de transporte e facilitar o gerenciamento do processo.

Segundo Muther (1978), a finalidade do planejamento de um arranjo físico gera indagações para muitos administradores, pois pequenas mudanças podem significar enormes ganhos de produtividade. Slack et al. (2002) avaliam que, por menor que sejam as mudanças em um layout, estas podem afetar o fluxo dos produtos, de informações e dos funcionários.

Além destes ganhos, Freitas et al. (2008) entendem que os benefícios da organização dos recursos produtivos para a promoção de um fluxo contínuo vão além da redução na movimentação. Dentre eles, o autor cita:

a) aumento da flexibilidade (produto e mão de obra);

b) aumento de produtividade;

c) redução de estoque em processo;

d) redução da área necessária à fabricação;

e) redução de movimentação de peças.

Pelo que foi colocado, gerir o arranjo físico é vital para uma empresa obter ganhos competitivos. A mudança de arranjo físico, porém, pode ser de execução difícil e cara e, portanto, os gerentes de produção podem relutar em fazê-la com frequência. Ao mesmo tempo, eles não podem errar em sua decisão (BORGES, 2001). A consequência de qualquer mau julgamento na definição do arranjo físico terá efeitos de longo prazo consideráveis na operação (SLACK et al., 2002). Assim, existem modelos de localização de leiaute que auxiliam nesta tomada de decisão.

Este tipo de decisão deve ser tomada em todos os tipos de empresas, inclusive nas empresas de tecnologia eletrônica, que são objetos de estudo deste artigo..

O presente artigo tem por objetivo fazer um estudo de leiaute em uma empresa que fabrica sensores de medição de velocidade de veículos e observar as vantagens que esta organização proporcionou para a redução dos custos de produção. Foram testados dois modelos tradicionais de leiaute: o celular e o funcional. 
Para tanto, o trabalho seguirá a seguinte estrutura: inicialmente, serão tecidas algumas considerações sobre arranjos físicos e tipos de leiautes. Em seguida, serão apresentados os modelos existentes para este tipo de planejamento. O terceiro ponto apresentará o estudo de caso desenvolvido na empresa em estudo, finalizando com os benefícios e conclusões do estudo.

\section{ARRANJOS FÍSICOS E LEIAUTE}

Chiavenato (2005) entende que arranjo físico é a forma como os recursos de produção estão distribuídos em uma manufatura de forma mais adequada ao processo produtivo. Esta organização tem papel fundamental no processo de uma empresa, pois, se bem montado, permitirá um caminho correto da primeira à última operação, reduzindo, desta forma, a circulação de mercadorias.

Segundo Peinado e Graeml (2007), o arranjo físico é a parte mais visível e exposta de qualquer organização. Assim, o arranjo físico é uma das características mais evidentes de uma operação produtiva porque determina sua "forma" e aparência. É aquilo que a maioria de nós notaria em primeiro lugar quando entrasse pela primeira vez em uma unidade produtiva (SLACK et al., 2002). Também determina a maneira segundo a qual os recursos transformados - materiais, informação e clientes - fluem pela operação. Vale ser ressaltado que, quanto maior a movimentação do produto, maior será seu custo operacional. Assim, a movimentação desnecessária não agrega valor ao produto e sim um custo, configurando-se como um desperdício.

De uma forma mais ampla, Prata (2002) define o arranjo físico como sendo a forma como são distribuídos os recursos de produção de uma empresa para que esta cumpra os objetivos para os quais se destina. Estes objetivos devem ser cumpridos buscando a maior eficiência possível. Logo, a organização destes recursos no ambiente fabril deve promover uma redução na movimentação e está adequada ao processo produtivo da empresa. Uma das formas de organizar os arranjos físicos é por meio dos estudos de leiaute.

Como já foi colocado, a redução dos desperdícios é vital para a sucesso das organizações. Krajewski et al. (2009) entendem que a revisão de leiaute é uma das formas de melhorar processos e reduzir custos. Os mesmos autores colocam que o objetivo de estudos como este é melhorar o fluxo produtivo, aumentando a produtividade.

Peinado e Graeml (2007) corroboram com a ideia que o estudo do arranjo físico se preocupa com a localização física dos recursos de transformação, o que vai estar intimamente relacionado com a melhoria dos fluxos produtivos.

O tipo de arranjo físico para máquinas e demais equipamentos de um sistema de manufatura assume relevante destaque, não somente em função dos processos, mas principalmente pela racionalização dos tempos de passagem dos lotes de peças entre os postos de trabalho (LORINI, 1993 apud PRATA, 2002). Isso confere uma maior redução de estoques, o que também se reflete em uma maior eficiência do processo.

Assim, Prata (2002) entende que o planejamento do arranjo físico tem como objetivo fundamental tornar mais fácil e suave o fluxo dos recursos transformados, que podem ser materiais ou pessoas, pelos recursos de transformação.

Krajewski et al. (2009) definem quatro questõs principais para o planejamento de um leiaute. São elas:

- Quais centros de trabalho deve incluir?

- De quanto espaço e capacidade cada centro precisará?

- Como o espaço de cada centro deve ser configurado?

- Onde cada centro deve estar localizado?

Estas questões devem ser respondidas e devem estar alinhadas com as estratégias de produção adotadas pela empresa. Cada tipo de leiaute está relacionado com o tipo de atividade produtiva desenvolvida 
pela empresa. Assim, o estudo do leiaute busca a combinação ótima das instalações que concorrem para a produção, proporcionando a fabricação de produtos com a melhor utilização do espaço disponível, resultando em um processamento mais efetivo, através da menor distância, no menor tempo possível.

Assim, o leiaute tem muitas implicações práticas e estratégicas dentro de uma organização, podendo citar: maximização da satisfação do cliente, facilitação do fluxo de materiais e informações, aumento da utilização eficiente dos recursos produtivos, redução de riscos para os trabalhadores, aumento do ânimo dos funcionários, dentre outras implicações (KRAJEWSKI et al., 2009).

Peinado e Graeml (2007) definem os principais tipos de leiautes:

- Arranjo por produto ou por linha;

- Arranjo por processo ou funcional;

- Arranjo celular;

- Arranjo por posição fixa;

- Arranjo misto.

Os tipos de arranjos são explicados nos subitens abaixo.

\subsection{Leiaute por produto ou em linha}

Krajewski et al. (2009) colocam que este tipo de organização deve ser utilizada para processos onde os fluxos de trabalho são lineares e as tarefas são repetitivas. Neste caso, as estações de trabalho ou departamentos são colocados em sequencia linear, onde o cliente ou produto se move ao longo de um fluxo regular e contínuo (KRAJEWSKI et al., 2009).

Peinado e Graeml (2007) identificam que este tipo de estruturação foi idealizada na fábrica de Herny Ford. Neste caso, as máquinas, os equipamentos ou as estações de trabalho são colocados de acordo com a sequência de montagem, sem caminhos alternativos para o fluxo produtivo. Este arranjo permite obter um fluxo rápido na fabricação de produtos padronizados, que exigem operações de montagem ou produção sempre iguais. Porém, o custo fixo da organização costuma ser alto, mas o custo variável por produto produzido é geralmente baixo, caracterizando um elevado grau de alavancagem operacional.

Dada esta característica, este tipo de leiaute não se aplica ao caso que será estudado, motivo pelo qual não foi estudada a possibilidade da utilização deste tipo de leiaute.

\subsection{Leiaute por processo}

O layout por processo consiste em centralizar em um mesmo local todas as máquinas destinadas a um tipo específico de operação, criando os conhecidos departamentos. Assim, Slack et al. (2002) colocam que, neste caso, processos similares são localizados um junto do outro.

Krajewski et al. (2009) entendem que processos de linha de frente e tarefas com fluxos de trabalho muito diferentes tem volume baixo e personalização alta. Na medida em que o roteiro de fabricação de determinado lote de peças exige uma operação, o mesmo é movimentado até o respectivo departamento para ser processado. Após a operação, o lote segue para o próximo departamento estabelecido no roteiro, até sua total conclusão (TUBINO, 2007).

Dentre as vantagens deste tipo de leiaute, Peinado e Graeml (2007) colocam: grande flexibilidade para atender a demandas de mercado, atende a produtos diversificados em quantidades variáveis ao mesmo tempo. A característica de flexibilidade para atender as demandas e produtos diversificados define este tipo de leiaute como candidato ao estudo de caso desenvolvido no presente artigo, dada a característica da empresa em questão. 
Assim, o arranjo físico por processo é assim chamado porque as necessidades e conveniências dos recursos transformadores que constituem o processo na operação dominam a decisão sobre arranjo físico. No arranjo por processo, processos similares (ou processos com necessidades similares) são localizados juntos um do outro. A razão pode ser que seja conveniente para a operação mantê-los juntos, ou que dessa forma a utilização dos recursos transformadores seja beneficiada (SLACK et al., 2002). Logo, Prata (2002) entende que, neste tipo de arranjo físico, todas as máquinas de um mesmo tipo são dispostas juntas, constituindose, assim, num arranjo típico de especialização por processo, porque as máquinas que realizam processos semelhantes ficam agrupadas numa mesma área física, no espaço da indústria.

Porém, normalmente, as distâncias a serem percorridas entre cada operação do roteiro de fabricação de um lote de itens é grande, gerando a necessidade de carregamento, transporte e descarregamento dos itens de máquina para máquina. Essas funções aumentam de complexidade e custos proporcionalmente ao tamanho dos lotes (TUBINO, 2007).

O grande desafio deste tipo de leiaute, porém, como coloca Silva e Cardoza (2010), é localizar cada setor dentro da empresa de forma a garantir um fluxo com menor tempo de processamento.

\subsection{Leiaute celular}

Segundo Peinado e Graeml (2007), o arranjo físico do tipo celular busca obter as vantagens do arranjo físico por processo, com as vantagens do arranjo físico por produto. Este tipo de arranjo procura localizar em um só local, conhecido como célula, máquinas diferentes que possam fabricar o produto inteiro.

O arranjo físico celular é aquele em que os recursos transformados, entrando na operação, são pré-selecionados para movimentar-se para uma parte específica da operação na qual todos os recursos transformadores necessários a atender a suas necessidades imediatas de processamento se encontram. (SLACK et al., 2002).

Assim, Prata (2002) entende que o arranjo físico celular concentra em um só local todos os recursos necessários ao processamento de um determinado produto previamente selecionado. Este tipo de organização minimiza o espaço percorrido pelo produto dentro da indústria.

O mesmo autor identifica uma característica muito importante do arranjo celular, que é a união das vantagens dos arranjos por processo e por produto. Os equipamentos de transformação são dispostos próximos uns dos outros e ainda se encontram na sequência adequada ao processo de produção. O autor ressalta que este layout apresenta flexibilidade de produção, pois é possível fabricar vários tipos de produtos desde que possuam características similares.

Esta é a característica mais distinta de uma célula de manufatura, que contém maquinário e/ou processos não semelhantes intimamente localizados numa área. Logo, a célula é projetada para manufaturar um conjunto mais ou menos definido de peças semelhantes, chamado de família de peças. (WERMMERLOV, 1997, apud PRATA, 2002). O autor explica que a especialidade de uma célula é possuir os equipamentos de transformação, que realizam operações diferentes, em um mesmo local.

Neste caso, Lorini (1993 apud PRATA, 2002) entende que as máquinas são arranjadas em grupos de tipos diversos, destinadas a atender inteiramente a fabricação, não mais de um determinado produto, mas de uma família de peças.

Assim, Chase et al. (2006) entendem que uma célula de manufatura conglomera diferentes máquinas em células de trabalho, onde famílias de produtos requerem aquelas atividades, com uma sequência integrada de fluxo de materiais e coordenada para o desempenho, como uma unidade operacional. 
Prata (2002) lista as seguintes vantagens do arranjo tipo celular:

- Redução de matéria-prima, de estoque em processo e inventário de produtos acabados;

- Tempo de setup reduzido;

- Os produtos são movidos de forma mais eficiente;

- Maior produtividade;

- Maior aproveitamento da mão-de-obra e satisfação dos operadores;

- Flexibilidade dos produtos e do tamanho dos lotes a serem fabricados.

Porém, não existem somente vantagens neste tipo de layout. O mesmo autor identifica algumas desvantagens:

- As máquinas geralmente possuem baixa utilização;

- As células podem requerer investimentos adicionais pela duplicação de equipamentos;

- Há um alto custo inicial pela realocação das máquinas;

- É exigida mais disciplina para evitar peças fora da família;

- Possibilidade de problemas ergonômicos.

\subsection{Leiaute por posição fixa}

Segundo Peinado e Graeml (2007), este tipo de arranjo é também conhecido por arranjo físico posicional, onde o produto permanece estacionário em uma determinada posição e os recursos de transformação se deslocam ao seu redor, executando as operações necessárias.

Dentre as principais vantagens deste tipo de leiaute, Peinado e Graeml (2007) citam: não movimentação do produto e existência da possibilidade de terceirização de todo o projeto ou parte dele com prazos previamente fixados.

Dentre as desvantagens, os mesmos autores citam a complexidade na supervisão e controle de mãode-obra, matéria-prima, etc e a necessidade de áreas externas próximas a produção para submontagem, guarda de matérias, etc.

Assim, com as considerações desenvolvidas acerca do tema que circunda o artigo, a próxima etapa apresenta o desenvolvimento do método de organização de produção desenvolvido no estudo de caso.

\section{SISTEMÁTICA DE DESENVOLVIMENTO DO MÉTODO}

A técnica mais difundida para o planejamento de leiaute é o planejamento sistemático de leiaute (SLP). Segundo Neumann e Milani (2009), o SLP auxilia o projetista a entender o que fazer ao longo do projeto de melhoria do leiaute, proporcionando economia de tempo e esforço.

Esta técnica se inicia com a coleta dos dados de entrada, para que se estabeleça os fluxos de matérias, representados numa carta "de-para" a fim de diferenciar a intensidade de fluxo entre os departamentos. A segunda etapa consiste na elaboração do diagrama de relacionamentos. Estes diagramas, segundo Slack et. al. (2002) retratam o quão desejável é manter pares de centros juntos uns dos outros. Trata-se de um método qualitativo de se indicar a importância relativa entre centros de trabalho. Este tipo de técnica ajuda a definir quais centros devem estar próximos uns dos outros, de forma a reduzir as distâncias percorridas (BORBA et al., 2010). 
Assim, os departamentos que tem a maior interação devem ser aproximados e vice-versa. Os próximos passos verificam a necessidade de espaço e o espaço disponível, determinando a quantidade de espaço a ser alocado para cada departamento (TOMPKINS et al.,1996 apud Neumann e Milani, 2009).

\subsection{Metodologia de transição de leiaute funcional para celular}

O mapa de relacionamento mostra o grau de importância entre departamentos, pessoas ou locais dentro de uma organização e é baseado na coleta de informações realizada na empresa. Neste artigo a metodologia utilizada baseou-se, inicialmente, na carta de relacionamentos de Slack et al.(2002), sendo desenvolvido em quatro fases discriminadas conforme o Quadro 1.

\begin{tabular}{c}
\hline Quadro 1 - Fases da transição funcional para celular \\
\hline $1^{\mathrm{a}} \mathrm{FASE}$ \\
\hline Coleta de informações \\
\hline $2^{\mathrm{a}} \mathrm{FASE}$ \\
\hline $\begin{array}{c}\text { Elaboração do diagrama de } \\
\text { relacionamentos }\end{array}$ \\
\hline $3^{\mathrm{a}} \mathrm{FASE}$ \\
\hline Elaboração do arranjo esquemático \\
\hline $4^{\mathrm{a}} \mathrm{FASE}$ \\
\hline Elaboração do arranjo físico
\end{tabular}

Na primeira fase, chamada de "coleta de informações", busca-se identificar as principais informações do setor de produção, como os produtos fabricados e os espaços físicos relacionados. Tem como objetivo a ambientação das atividades do setor. Esta fase é composta pelas subetapas descritas a seguir (SLACK et al., 2002):

- Identificação dos produtos principais: conhecer os principais produtos da empresa e suas principais características. É realizado um levantamento destas informações através de entrevistas com os funcionários do setor e observações do dia-a-dia das operações.

- Medidas dos espaços físicos: realização de um levantamento dos espaços físicos relevantes para a elaboração do layout com as áreas ocupadas e também realiza-se um levantamento para verificação da área disponível.

- Identificar os espaços dos objetos atuais: Identificação do estoque de matéria-prima, estoque em processo, estoque de produtos acabados, máquinas, postos de trabalho, veículo de transporte e outros.

- Identificar o espaço disponível: espaço onde ficará o setor de produção. Nesta etapa é feita uma breve comparação dos espaços dos objetos atuais com o espaço disponível.

A segunda fase do processo é a elaboração do diagrama de relacionamentos. Ele deve ser elaborado pelo gestor do setor, que possui experiência para indicar o grau de relação entre os centros.

A terceira fase é estruturação esquemática do desenho do arranjo, que demonstra a relação entre os centros. Essa relação varia em seis níveis. Quanto mais forte for a relação, mais espessa será a linha de ligação entre cada centro.

Como última fase do processo, tem-se o desenho do arranjo físico, em que é elaborado o arranjo físico real do setor de produção com base no arranjo físico esquemático, o qual foi elaborado na fase anterior. 


\subsection{Metodologia de transição de layout celular para funcional}

No segundo modelo utilizado, neste caso para uma nova transição do layout celular para o funcional, a sistemática utilizada baseou-se na carta de processo de Muther (1978). O Quadro 2 ilustra as etapas deste processo.

\begin{tabular}{c}
$\frac{\text { Quadro 2 - Fases da transição celular para funcional }}{1^{\mathrm{a}} \mathrm{FASE}}$ \\
\hline Coleta de informações \\
\hline $2^{\mathrm{a}} \mathrm{FASE}$ \\
\hline Desenho da rede de processos \\
\hline $3^{\mathrm{a}} \mathrm{FASE}$ \\
\hline Agrupamento dos processos \\
semelhantes \\
\hline $4^{\mathrm{a}}$ FASE \\
\hline Desenho do arranjo físico
\end{tabular}

$\mathrm{Na}$ primeira fase, chamada de coleta de informações, é realizada a identificação das principais informações sobre a sequência cronológica de operações e como e quando os componentes são reunidos. Esta fase é composta pelas seguintes etapas (SLACK et al., 2002):

- Montar estrutura do produto: Definir a composição do produto da empresa, contendo a especificação de todos os seus componentes e suas respectivas quantidades.

- Listar os processos de montagem: Agrupar os materiais para a realização das montagens. A especificação de cada processo reúne os componentes com o objetivo de produzir o produto final.

A segunda fase contempla o desenho da rede de processos, em que são realizadas análises de precedência para cada processo, sendo informados quais os processos que antecedem cada montagem. A técnica utilizada para documentar esta rede foi o diagrama de fluxo simples, o qual é utilizado para identificar os principais elementos de um processo de montagem.

A terceira fase do método busca agrupar processos semelhantes em cada posto, analisando, baseado no diagrama de fluxo simples, o posto onde cada processo é realizado. O agrupamento de processos com características semelhantes irá permitir a elaboração do novo arranjo físico.

Por último, tem-se a quarta fase, em que o arranjo físico é desenhado com base nos processos de montagem.

Em seguida, será apresentado o estudo de caso realizado.

\section{ESTUDO DE CASO}

\subsection{Caracterização do estudo de caso}

A empresa focada neste estudo é responsável pela produção de sensores de velocidade. Foi criada em 1993 e fabrica equipamentos de fiscalização de trânsito, softwares para dar suporte a estes equipamentos de campo e sistemas de auxílio de emergências no trânsito georeferenciado. Vale ser ressaltado que a empresa em questão foi criada na incubadora localizada no campus da Universidade Federal do Ceará. Esta empresa trabalha com licitações para fornecimento e manutenção dos equipamentos de controle de velocidade e atua em várias cidades brasileiras.

A empresa possui três andares principais, o térreo, primeiro andar e segundo andar, que estão interligados por escada e por elevador. O envio e recebimento de mercadoria são realizados por trás do prédio que está 
num nível um pouco abaixo do térreo, sendo separado por uma escada. Na sua configuração inicial, antes de qualquer mudança de leiaute, o envio e recebimento de mercadoria são realizados por trás do prédio que está num nível abaixo do térreo, sendo separado por uma escada.

Bastante incomum, a UGB (Unidade Geral Básica) Produção estava, inicialmente, localizada no segundo andar, representando dificuldades na movimentação dos equipamentos. $\mathrm{O}$ acesso à área de expedição não possui ligação por elevador; logo, todos os equipamentos devem sempre passar por uma escada com alguns degraus.

Outro fator crítico é o super dimensionamento desta UGB no segundo andar. Com aproximadamente $278 \mathrm{~m}^{2}$, havia movimentação desnecessária dos técnicos entre as mesas de montagem, estantes dos materiais e as bancadas. A Figura 1 ilustra o leiaute inicial da empresa.

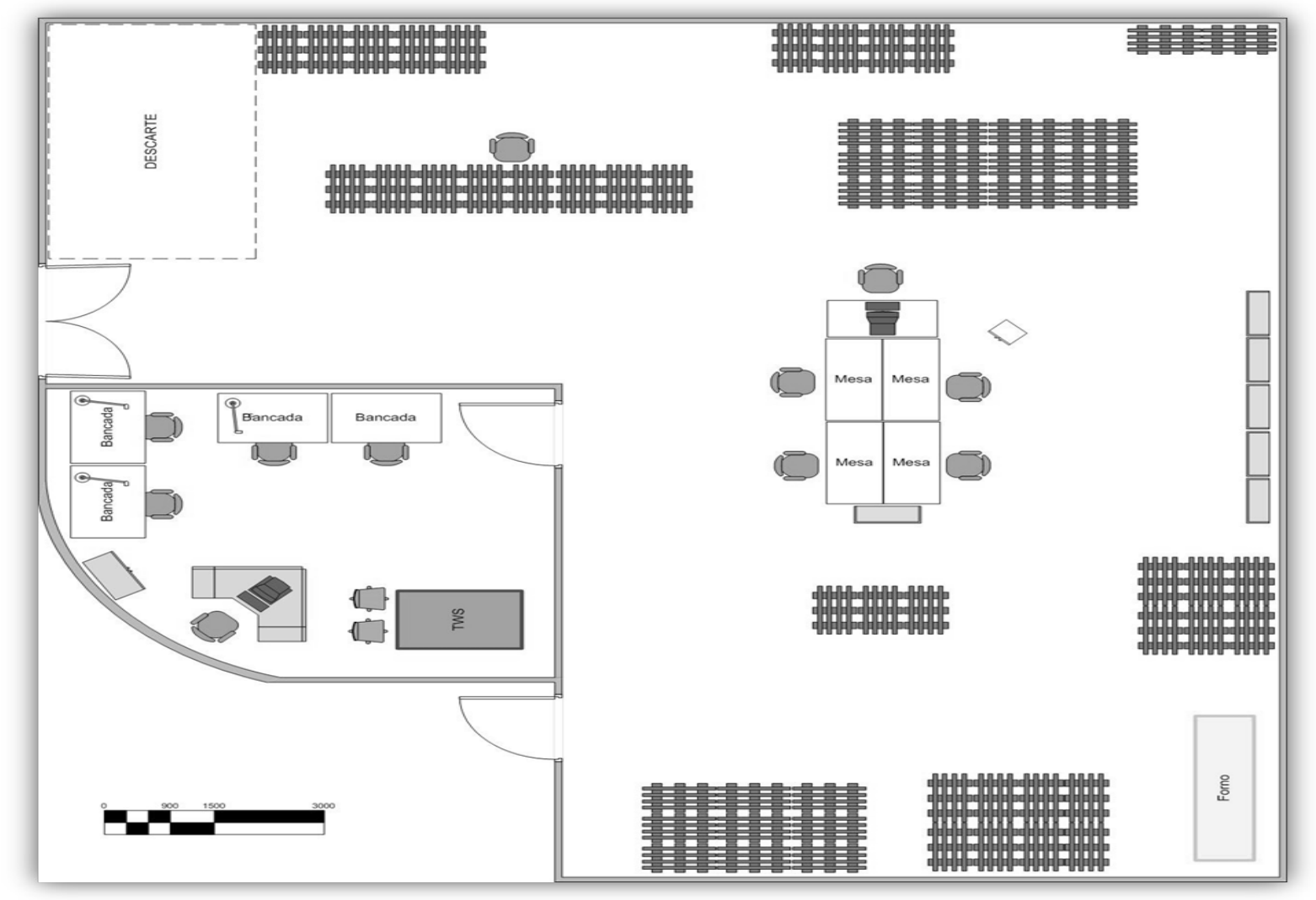

Figura 1 - Leiaute da UGB Produção no $3^{\circ}$ andar

A Figura 1 ilustra o leiaute da UGB Produção no segundo andar do prédio. Trata-se da área onde estão localizadas as bancadas e tudo é climatizado. Os objetos com formato de cerca representam as paletes. As estantes estão localizadas ao lado direito e estão distantes cinco metros das mesas de montagem e quatorze metros das bancadas. Compreendem dezesseis metros o percurso entre a TWS - robô, que realiza montagens de placas, e o forno. Esses dois equipamentos permitem a fabricação de placas com componentes de tecnologia SMD. Após a montagem, a placa deve ir ao forno para um correto tratamento da solda.

O setor de maior interligação com a Produção é o Almoxarifado e a Logística que se encontram na outra extremidade do prédio. Por todas estas características apresentadas, observou-se que a estrutura de layout não era satisfatória para o desempenho requerido pela empresa. Assim, foi elaborado um modelo para modificação do arranjo físico, passando este para a modalidade celular. $\mathrm{O}$ sub-tópico a seguir ilustra o desenvolvimento deste modelo na empresa estudada. 
Os produtos fabricados pela empresa possuem dois tipos de tecnologia:

- SMTP: Sistema de Monitoramento de Tráfego Película (SMTP) possui uma câmera fotográfica que utiliza filmes de revelação. É um sistema antigo, porém é robusto e apresenta problemas de manutenção menores quando comparado ao Sistema Digital. A própria caixa de câmera contém toda a estrutura do equipamento.

- SMTD: Sistema de Monitoramento de Tráfego Digital (SMTD) é um equipamento moderno, apresenta um processo de fabricação mais complexo; logo, possui mais componentes, como placa de detecção, placa mãe, processador, memória, placa de captura, entre outros itens. Este sistema é composto por caixa de câmera, gabinete externo e gabinete interno. De acordo com a necessidade da via e do órgão de trânsito, o SMTD apresenta vários modelos, sendo possível monitorar uma, duas, três ou quatro faixas. De acordo com a capacidade de monitoramento, haverá um maior ou menor número de componentes de hardware.

Dada a especificidade de cada uma das licitações, o leiaute incialmente utilizado pela empresa é o funcional, pelos motivos colocados no referencial teórico. Porém, se observava na empresa um grande desperdício oriundo das movimentações desnecessárias entre departamentos. Assim, optou-se em fazer um estudo do leiaute desta empresa.

Inicialmente, foi proposto um estudo de mudança para a configuração celular. Logo, constatou-se que o arranjo produtivo da empresa em questão estava com ineficiências na movimentação dos materiais, onde os produtos percorriam distâncias grandes durante o processo. Assim, para melhorar este aspecto, foi proposto a transição do arranjo funcional para o celular, dados os benefícios que pode apresentar em relação ao modelo vigente.

\subsection{Implantação do modelo funcional para o celular}

Na primeira fase do processo, a coleta de informações, observou-se aspectos negativos da localização do setor de produção, que se localizava no terceiro andar, não interligado por elevador. Observou-se que a área total do terceiro andar possuía $277 \mathrm{~m}^{2}$. Assim, foi tomada uma decisão estratégica de mudança de local, passando a ser localizado no andar térreo. Levantou-se também a área total disponível no andar térreo, com apenas $96 \mathrm{~m}^{2}$.Com esta mudança, foram identificadas algumas vantagens iniciais:

- Setor de Produção mais próximo da UGB (Unidade de Gerenciamento Básico) Almoxarifado;

- Setor de Produção mais próximo da UGB Logística;

- Não há escadas durante a movimentação de material pesado.

Porém, com a mudança, pôde ser observado algumas desvantagens deste novo modelo implantado. As mesmas são listadas a seguir:

- Espaço no térreo muito pequeno, com aproximadamente $96 \mathrm{~m}^{2}$;

- Existência de colunas de alvenaria que dificultam a distribuição dos objetos e das passagens.

Seguindo a metodologia proposta, foi realizado um levantamento da área e dos objetos do setor, dividindo-se o espaço dos objetos em seis grupos principais conforme a Tabela 1.

Assim, pela Tabela 1, pode-se observar que a área física requerida para todos os objetos detalhados é de $66,16 \mathrm{~m}^{2}$. A área livre para circulação (área total subtraída da área dos objetos) do terceiro andar é de $211 \mathrm{~m}^{2}$. Esta área de circulação representa $76 \%$ da área total, o que permite um bom fluxo dos materiais e das pessoas, porém com distâncias que mereciam redução. Se fossem alocados todos os objetos presentes no terceiro andar para a área destinada no térreo, a área para circulação seria de apenas $30 \mathrm{~m}^{2}$, que representa apenas $31 \%$ da área total. A Tabela 2 ilustra estes fatos. 
Tabela 1 - Área dos objetos da Produção

\begin{tabular}{|c|c|c|c|c|}
\hline Estoques em processo & Qtd paletes* & Largura & Comprimento & Área $\left(\mathrm{m}^{2}\right)$ \\
\hline Gabinete externo SMTd pré-montado & 8 & 4,8 & 1 & 4,80 \\
\hline Gabinete interno SMTd pré-montado & 5 & 3 & 1 & 3,00 \\
\hline Caixa de display SMTP 9010 pré-montado & 4 & 2,4 & 1 & 2,40 \\
\hline Caixa de câmera SMTd pré-montado & 2 & 1,2 & 1 & 1,20 \\
\hline Caixa de câmera SMTP pré-montado & 6 & 1,8 & 2 & 3,60 \\
\hline Estoques de matérias-primas & Qtd paletes & Largura & Comprimento & Área $\left(\mathrm{m}^{2}\right)$ \\
\hline Caixa do gabinete interno SMTd & 9 & 3 & 1,8 & 5,40 \\
\hline Material para montagem do SMTP & 2 & 1 & 1,2 & 1,20 \\
\hline Estante para fabricados de terceiro & 5 & 0,93 & 0,31 & 0,29 \\
\hline Estante de pequenas peças & 1 & 0,91 & 0,35 & 0,32 \\
\hline Tampas das bandejas para SMTd & 2 & 1 & 1,2 & 1,20 \\
\hline Bandejas para SMTd & 2 & 1 & 1,2 & 1,20 \\
\hline Tampas dos gabinetes externos SMTd & 3 & 3 & 0,6 & 1,80 \\
\hline Material para gabinete interno SMTd & 2 & 1 & 1,2 & 1,20 \\
\hline Estoques de produtos acabados & Qtd paletes & Largura & Comprimento & Área $\left(\mathrm{m}^{2}\right)$ \\
\hline Caixa de câmera do SMTP montada & 8 & 2,4 & 2 & 4,80 \\
\hline Caixa de display SMTP 9010 montada & 3 & 1,8 & 1 & 1,80 \\
\hline Caixa do gabinete externo SMTd & 1 & 1 & 0,6 & 0,60 \\
\hline Máquinas & Qtd & Largura & Comprimento & Área $\left(\mathrm{m}^{2}\right)$ \\
\hline Máquina de solda (forno) & 1 & 3 & 0,8 & 2,40 \\
\hline Máquina TWS Automation & 1 & 1,7 & 1,2 & 2,04 \\
\hline Postos de trabalho & Qtd & Largura & Comprimento & Área $\left(\mathrm{m}^{2}\right)$ \\
\hline Bancada de montagem & 4 & 1,5 & 1 & 6,00 \\
\hline Mesa de montagem & 1 & 4,1 & 1,6 & 6,56 \\
\hline Cadeiras & 6 & 0,6 & 0,6 & 2,16 \\
\hline Outros & Qtd & Largura & Comprimento & Área $\left(\mathrm{m}^{2}\right)$ \\
\hline Área de descarte e classificação & 1 & 6 & 2 & 12,00 \\
\hline Gaveteiro & 1 & 0,62 & 0,31 & 0,19 \\
\hline
\end{tabular}

* Representa a quantidade de paletes que acomodam os estoques.

Diante dos desafios, foi elaborado um diagrama de relacionamentos que permitiu verificar quais os objetos da Tabela 1 realmente seriam importantes permanecerem dentro do setor.

Assim, foi realizada uma entrevista com o gestor do setor para a classificação da relação entre as operações desenvolvidas na área de produção. Foram também definidos códigos para cada objeto presente no leiaute. Para a elaboração do diagrama de relacionamentos, foi solicitado ao gestor da UGB Produção que relacionasse todas as áreas e objetos utilizados no setor de produção. O Quadro 3 apresenta os critérios utilizados no relacionamento de cada área e objeto.

Tabela 2 - Comparação de áreas

\begin{tabular}{|c|c|c|}
\hline Descrição & $\left(\mathrm{m}^{2}\right)$ & $\begin{array}{l}\text { Percentual } \\
(\%)\end{array}$ \\
\hline Area total no $3^{\circ}$ andar & 277 & $100 \%$ \\
\hline Área dos objetos & 66 & $24 \%$ \\
\hline Área para circulação no $3^{\circ}$ andar & 211 & $76 \%$ \\
\hline Area total no térreo & 96 & $100 \%$ \\
\hline Área dos objetos & 66 & $69 \%$ \\
\hline Área para circulação no térreo & 30 & $31 \%$ \\
\hline
\end{tabular}




\begin{tabular}{|c|c|c|c|c|c|c|}
\hline CÓDIGO & $\mathbf{A}$ & $\mathbf{E}$ & $\mathbf{I}$ & $\mathbf{O}$ & $\mathbf{U}$ & $\mathbf{X}$ \\
\hline PROXIMIDADE & $\begin{array}{l}\text { ABSOLUTAMENTE } \\
\text { NECESSÁRIO }\end{array}$ & $\begin{array}{l}\text { ESPECIALMENTE } \\
\text { IMPORTANTE }\end{array}$ & IMPORTANTE & $\begin{array}{l}\text { PROXIMIDADE } \\
\text { NORMAL }\end{array}$ & $\begin{array}{c}\text { NÃO } \\
\text { IMPORTANTE }\end{array}$ & INDESEJÁVEL \\
\hline
\end{tabular}

Fonte: Adaptado de Slack, Chambers e Johnston (2002, p.219).

Em seguida, foi elaborado o diagrama de relacionamentos. A Figura 2 ilustra o diagrama obtido.

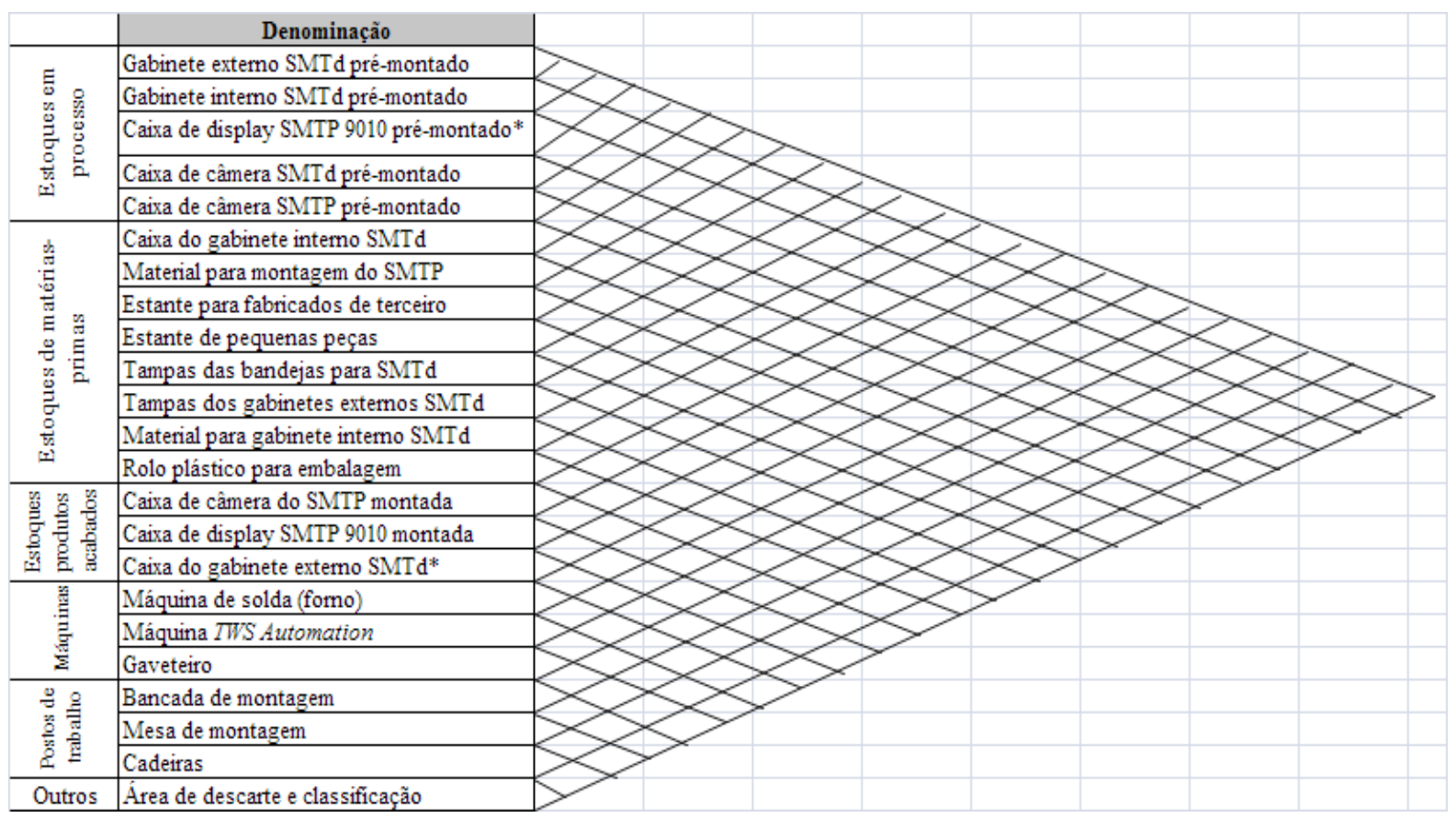

Figura 2 - Diagrama de Relacionamentos

Com o diagrama de relacionamentos, foi elaborada uma tabela de pontuação para todos os objetos presentes no leiaute. Os códigos de pontuação são ilustrados no Quadro 4.

Quadro 4 - Códigos de pontuação

\begin{tabular}{|c|c|c|c|c|c|}
\hline $\mathbf{A}$ & $\mathbf{E}$ & $\mathbf{I}$ & $\mathbf{O}$ & $\mathbf{U}$ & $\mathbf{X}$ \\
\hline 4 & 3 & 2 & 1 & 0 & -1 \\
\hline
\end{tabular}

Fonte: Adaptado de Slack et al. (2002).

Após o preenchimento do diagrama de relacionamentos pelo gestor da UGB Produção, a equipe de consultoria realizou a compilação dos códigos para cada objeto conforme Tabela 3.

Esta etapa permitiu que fossem avaliados que componentes devem estar próximos entre si e quais podem estar mais distantes. O objetivo, neste caso, é a redução do deslocamento entre as etapas do processo produtivo. Esta pontuação está ilustrada na Tabela 4.

Assim, o diagrama de relacionamentos permitiu a identificação dos seguintes pontos críticos:

- As estantes devem estar localizadas nos pontos mais centrais do setor de produção, devido ao elevado percentual de relacionamento; 
- As bancadas e a mesa de montagem devem estar próximas às estantes e em posições centrais do arranjo;

- Os estoques em processo deverão estar próximos das áreas acima citadas;

- O gaveteiro, contendo o ferramental, deverá estar tão próximo quanto possível das áreas onde ocorre o processo de produção;

Tabela 3 - Códigos atribuídos

\begin{tabular}{|c|c|c|}
\hline & & Denominação \\
\hline \multirow{5}{*}{ 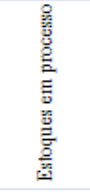 } & 1 & Gabinete externo SMTd pré-montado \\
\hline & 2 & Gabinete interno SMTd pré-montado \\
\hline & 3 & Caixa de display SMTP 9010 pré-montado* \\
\hline & 4 & Caixa de câmera SMTd pré-montado \\
\hline & 5 & Caixa de câmera SMTP pré-montado \\
\hline \multirow{8}{*}{ 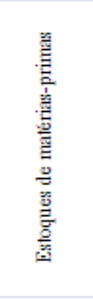 } & 6 & Caixa do gabinete interno SMTd \\
\hline & 7 & Material para montagem do SMTP \\
\hline & 8 & Estante para fabricados de terceiro \\
\hline & 9 & Estante de pequenas peças \\
\hline & 10 & Tampas das bandejas para SMTd \\
\hline & 11 & Tampas dos gabinetes externos SMTd \\
\hline & 12 & Material para gabinete interno SMTd \\
\hline & 13 & Rolo plástico para embalagem \\
\hline \multirow{3}{*}{ 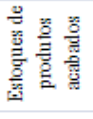 } & 14 & Caixa de câmera do SMTP montada \\
\hline & 15 & Caixa de display SMTP 9010 montada \\
\hline & 16 & Caixa do gabinete externo SMTd* \\
\hline \multirow{3}{*}{ 兽 } & 17 & Máquina de solda (forno) \\
\hline & 18 & Máquina TWS Automation \\
\hline & 19 & Gaveteiro \\
\hline \multirow{3}{*}{ 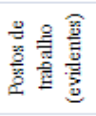 } & 20 & Bancada de montagem \\
\hline & 21 & Mesa de montagem \\
\hline & 22 & Cadeiras \\
\hline Outros & 23 & Área de descarte e classificação \\
\hline
\end{tabular}

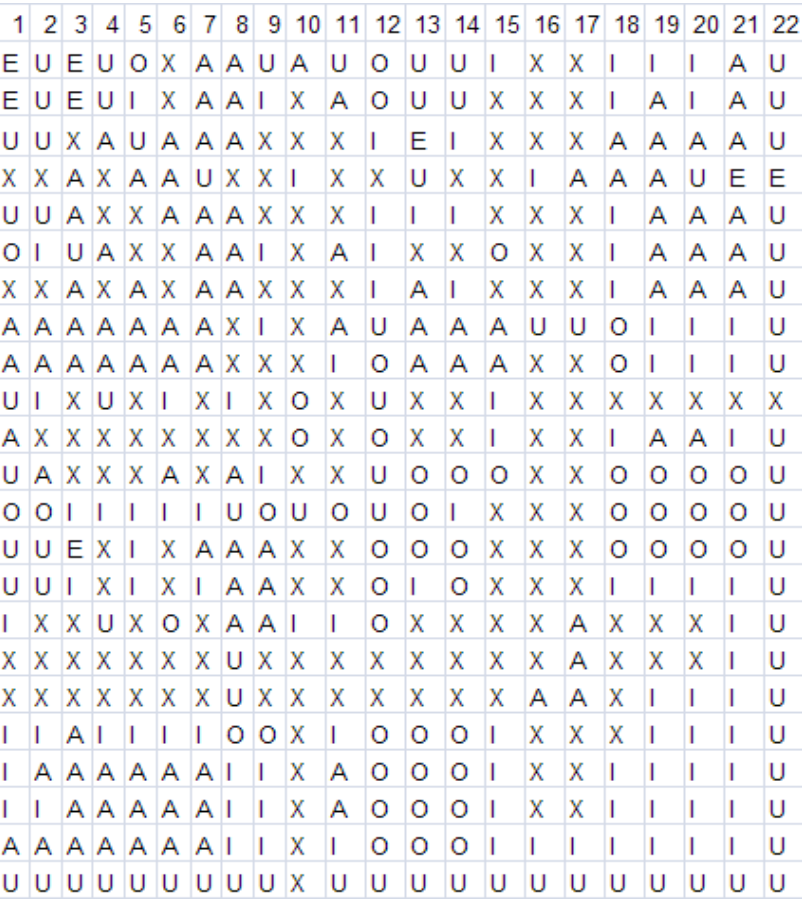

Tabela 4 - Pontuação acumulada

\begin{tabular}{|l|c|c|c|}
\multicolumn{1}{|c|}{ OBJETO } & PT & PT $\%$ & $\%$ AC \\
\hline Estante para fabricados de terceiro & $\mathbf{5 1}$ & $\mathbf{1 0} \%$ & $\mathbf{1 0} \%$ \\
\hline Cadeiras & $\mathbf{5 0}$ & $\mathbf{9} \%$ & $\mathbf{1 9} \%$ \\
\hline Estante de pequenas peças & $\mathbf{4 5}$ & $\mathbf{9} \%$ & $\mathbf{2 8} \%$ \\
\hline Bancada de montagem & $\mathbf{4 4}$ & $\mathbf{8} \%$ & $\mathbf{3 6} \%$ \\
\hline Mesa de montagem & $\mathbf{4 2}$ & $\mathbf{8} \%$ & $\mathbf{4 4} \%$ \\
\hline Caixa de display SMTP 9010 pré-montado* & $\mathbf{3 2}$ & $\mathbf{6} \%$ & $\mathbf{5 0} \%$ \\
\hline Caixa do gabinete intemo SMTd & 31 & $6 \%$ & $56 \%$ \\
\hline Gabinete interno SMTd pré-montado & 30 & $6 \%$ & $62 \%$ \\
\hline Gabinete externo SMTd pré-montado & 29 & $5 \%$ & $67 \%$ \\
\hline Caixa de câmera SMTP pré-montado & 28 & $5 \%$ & $72 \%$ \\
\hline Material para montagem do SMTP & 28 & $5 \%$ & $78 \%$ \\
\hline Gaveteiro & 27 & $5 \%$ & $83 \%$ \\
\hline Caixa de câmera SMTd pré-montado & 25 & $5 \%$ & $88 \%$ \\
\hline Caixa de display SMTP 9010 montada & 19 & $4 \%$ & $91 \%$ \\
\hline Rolo plástico para embalagem & 18 & $3 \%$ & $95 \%$ \\
\hline Caixa de câmera do SMTP montada & 17 & $3 \%$ & $98 \%$ \\
\hline Material para gabinete intemo SMTd & 13 & $2 \%$ & $100 \%$ \\
\hline Caixa do gabinete externo SMTd & 11 & $2 \%$ & $102 \%$ \\
\hline Tampas dos gabinetes extemos SMTd & 7 & $1 \%$ & $104 \%$ \\
\hline Máquina TWS Automation & -1 & $0 \%$ & $103 \%$ \\
\hline Área de descarte e classificação & -1 & $0 \%$ & $103 \%$ \\
\hline Tampas das bandejas para SMTd & -5 & $-1 \%$ & $102 \%$ \\
\hline Máquina de solda (forno) & -12 & $-2 \%$ & $100 \%$ \\
\hline
\end{tabular}


Outras áreas deverão ser reduzidas ao máximo, ou eliminadas, nomeadamente de estoques de matériasprimas, para que no setor de produção estejam somente os materiais que venham a ser utilizados em curto ou curtíssimo tempo. A caixa do gabinete externo é uma exceção devido ao seu peso elevado; entretanto, convém que sejam reduzidos os lotes desses materiais na área destinada à produção.

Com os dados obtidos nesta primeira análise, a fase seguinte do processo foi o desenho do arranjo esquemático, que foi realizada atribuindo-se espessuras e tipos de linhas diferentes para cada grau de proximidade entre os objetos. As áreas com proximidade indesejável não foram ligadas; porém, tomou-se o cuidado de afastá-las no desenvolvimento do layout. A Figura 3 ilustra o que foi obtido.

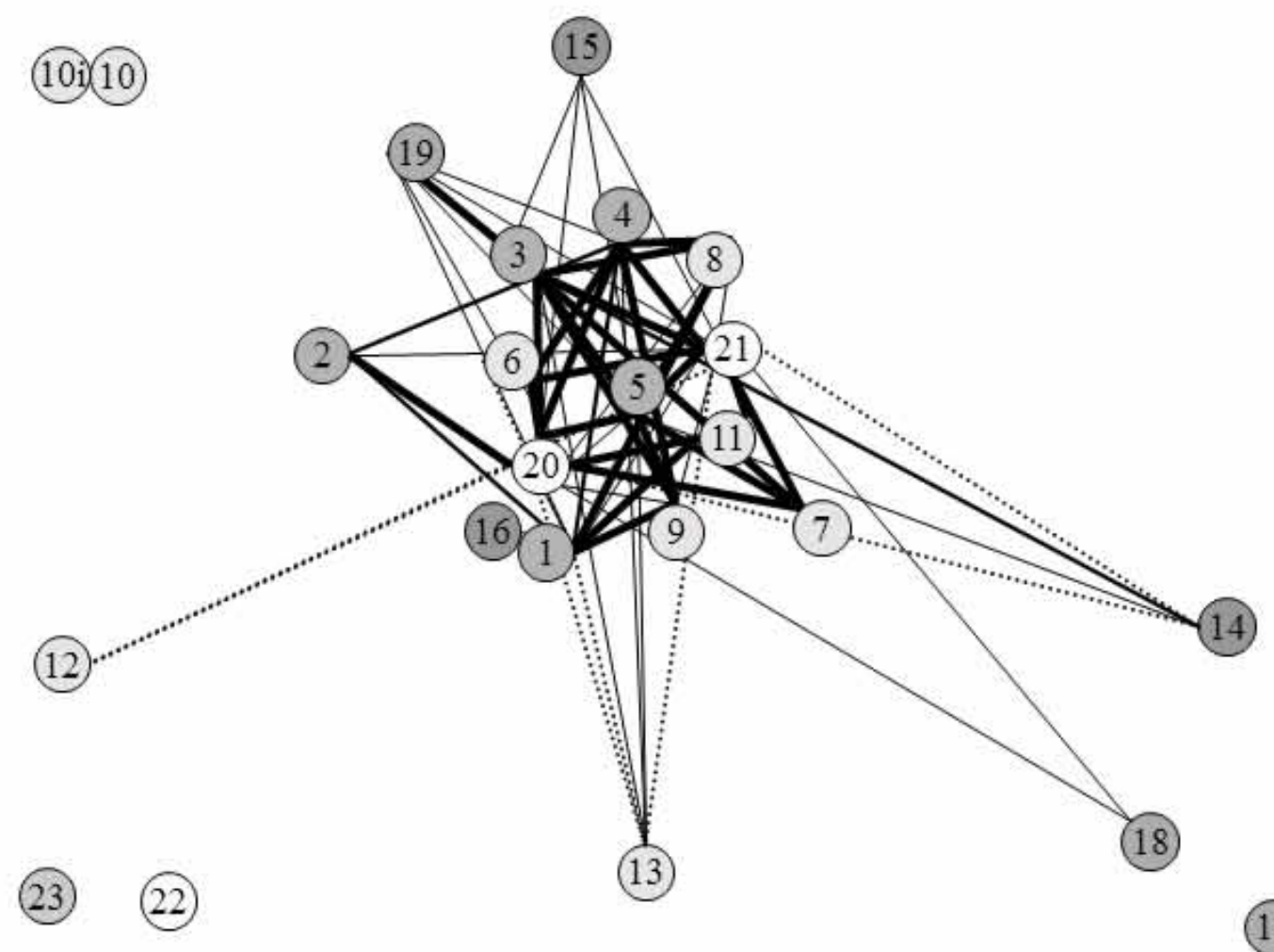

Figura 3 - Arranjo esquemático

$\mathrm{Na}$ Figura 3, cada ponto significa um posto de trabalho do setor. Como se pode observar, os pontos $20 \mathrm{e}$ 21, respectivamente bancada e mesa de montagem, apresentam fortes ligações com os outros objetos, devendo estar centralizados dentro da UGB Produção. Adicionalmente, verifica-se que o ponto 9, representando as estantes, deve estar equidistante das bancadas e da mesa de montagem. O ponto 8, estante de pequenas peças, deve estar mais próximo da mesa que das bancadas. Por fim, nota-se que os pontos em cinza, 1 a 5 , que representam o estoque em processo, devem estar tanto mais próximos das bancadas e mesa quanto possível.

Por último, com base no arranjo esquemático, foi elaborado o desenho do arranjo físico, em que se fizeram os ajustes para que cada área e objeto fossem alocados nos locais mais adequados, permitindo, sobretudo, um bom fluxo de pessoas e materiais, bem como um espaço para a realização ótima das atividades produtivas. Este novo leiaute obtido está ilustrado na Figura 4.

Por esta Figura, pode-se observar que os objetos que possuem maior relacionamento com os demais que estão localizados na parte central do leiaute proposto e o restante ao seu redor. 


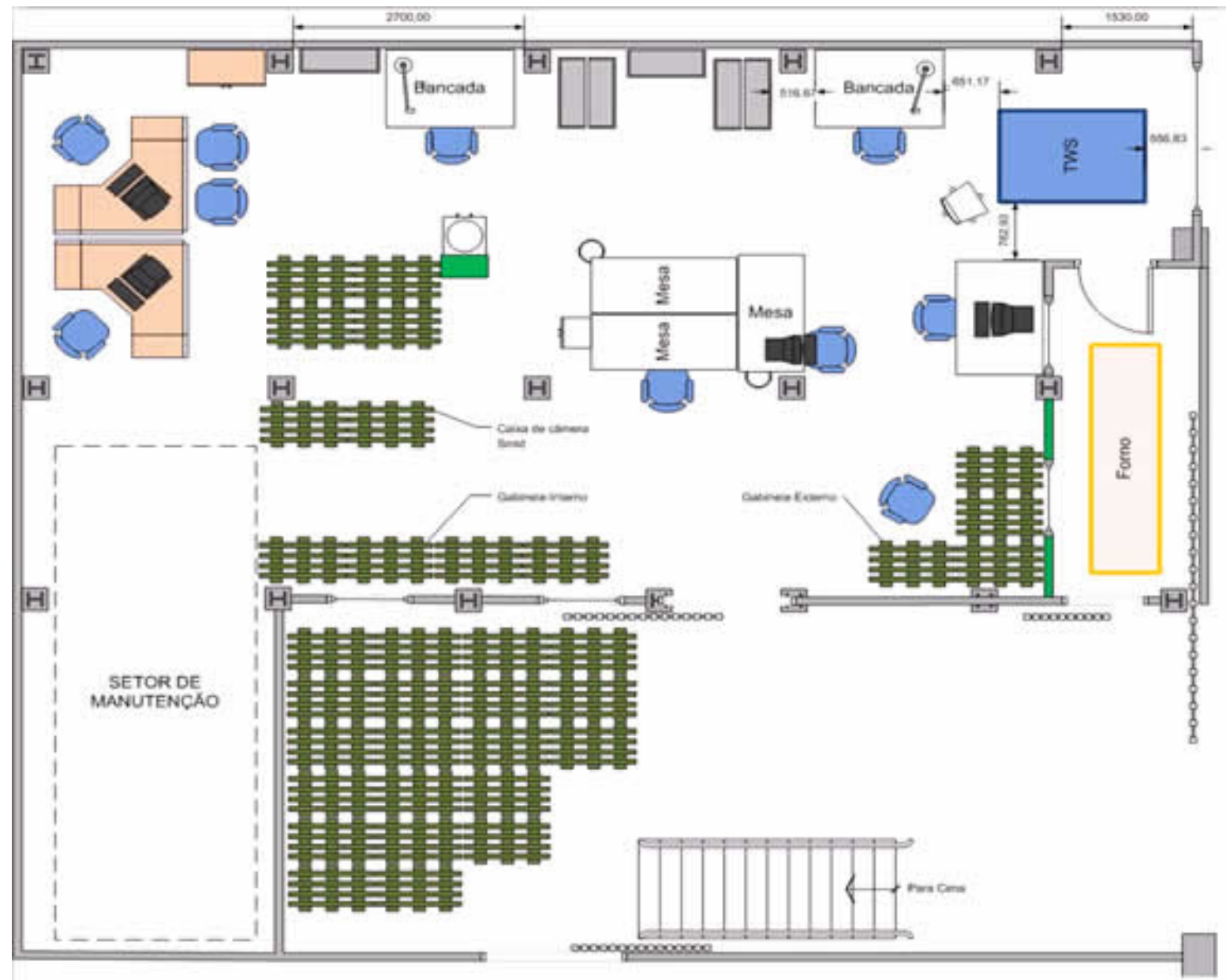

Figura 4 - Leiaute celular desenvolvido

\subsubsection{Vantagens e desvantagens do modelo}

O leiaute desenvolvido permitiu grande redução de movimento dos técnicos entre mesa de montagem e as estantes, visto que a distância inicial era de 5 metros passando para 2,5m (redução de 50\%). A distância inicial entre as bancadas e estantes eram de $14 \mathrm{~m}$ passando a apenas $2,5 \mathrm{~m}$ (redução de $82 \%$ ). O percurso entre a TWS (máquina de soldagem em placas) e o Forno obteve os maiores ganhos, com trajeto de $16 \mathrm{~m}$ para apenas $2 \mathrm{~m}$ (redução de 88\%).

Alguns meses após o desenvolvimento do leiaute celular e instalação do setor de produção no piso inferior do prédio, ocorreu um avanço tecnológico no SMTD. Foi criado uma versão mais compacta denominada SMTDI - Sistema de Monitoramento de Tráfego Digital Integrado, pois este integra os três componentes básicos do SMTD. Dessa forma será produzido mais um tipo de equipamento, o qual exigirá mais espaços do setor de produção.

Nesse mesmo período foi iniciada a implantação do ERP na empresa. Tal sistema necessitará de uma precisão de informações sobre estoque da produção, o que exigirá maior organização interna da UGB. Essa organização exigirá locais apropriados para estocagem provisória dos cabos, placas, fontes entre outros diversos insumos utilizados nos equipamentos.

Pelos acontecimentos listados acima, observou-se que este tipo de arranjo ainda não se adequava à realidade da empresa, não conseguindo maximizar sua produtividade. Assim, foi proposto um novo leiaute, sendo detalhada a metodologia adotada a seguir. 


\subsection{Proposta de leiaute funcional para o setor de produção}

Para a primeira fase, coleta de informações, foi levantada a estrutura macro de um modelo fabricado na empresa (SMTD Velocidade 2 Faixas), ilustrado na Figura 5.

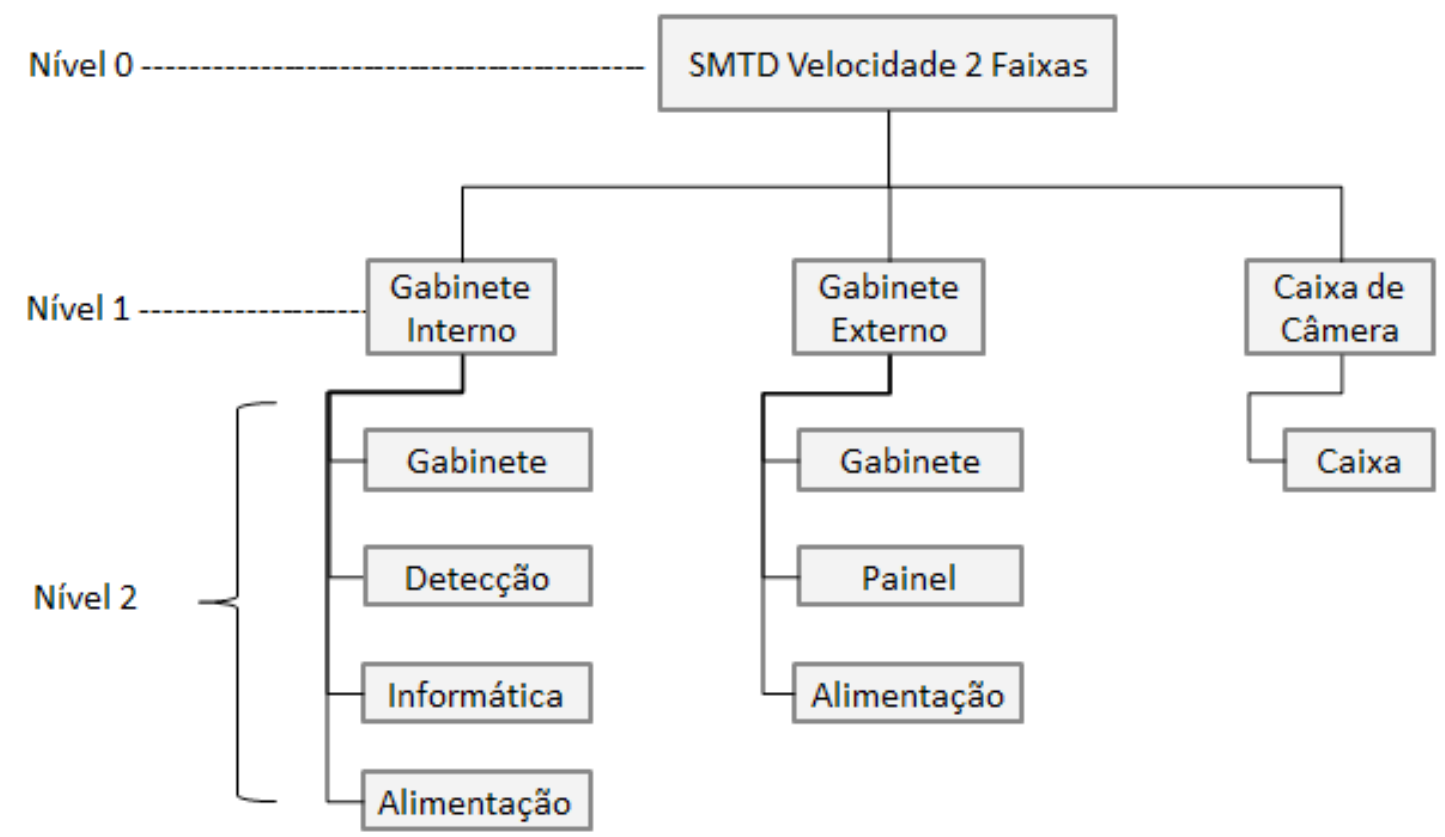

Figura 5 - Estrutura do produto SMTD v2fx

Este produto possui três ramificações principais (Gabinete Interno, Gabinete Externo e Caixa de Câmera) onde estas se formam em várias sub-ramificações formando uma estrutura do produto de 4 níveis. Para cada módulo apresentado, existe uma relação de itens que os compõem. Para cada módulo, foram descritos os itens englobados no mesmo.

$\mathrm{Na}$ segunda fase, foi desenhada a rede de processos a partir da estrutura do produto, identificando os processos macro de montagem do SMTD. O primeiro componente é a caixa de câmera, na qual a rede e a listagem dos processos estão representadas na Figura 6.

Como pode-se observar na Figura 7, a caixa de câmera possui 6 processos. Em seguida, tem-se o Gabinete Interno, para o qual também foi desenhado a rede de processos a partir da estrutura do produto. O Gabinete Externo possui 12 processos detalhados na Figura 7.

Já o gabinete interno possui 27 processos. Para melhor compreensão da rede, foi definida uma cor e uma sigla para cada módulo do gabinete interno. Como exemplo, os processos que iniciam com a letra $\mathrm{D}$ referem-se ao módulo de detecção. A lista dos processos está indicada na Tabela 5.

Com a lista de processos ilustrada na Tabela 5, observa-se a relação entre estes processos na Figura 8.

A terceira fase da metodologia engloba o agrupamento dos processos semelhantes em cada posto. Após a montagem da rede, foi possível identificar o posto de trabalho onde é feito cada processo. A Figura 9 identifica por cores o tipo de posto onde ocorrem as montagens e adaptações. Percebe-se que há um grande número de operações no posto de cor branca e uma quantidade significativa no posto de cor preta. 


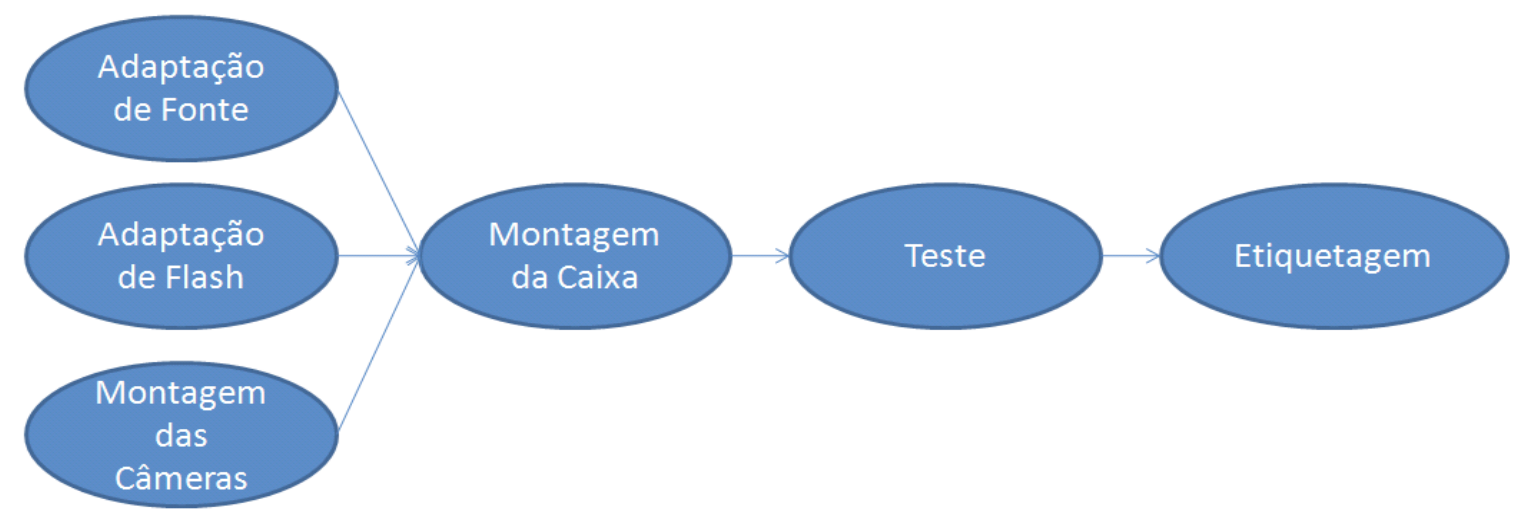

Figura 6 - Rede de processos da caixa de câmera

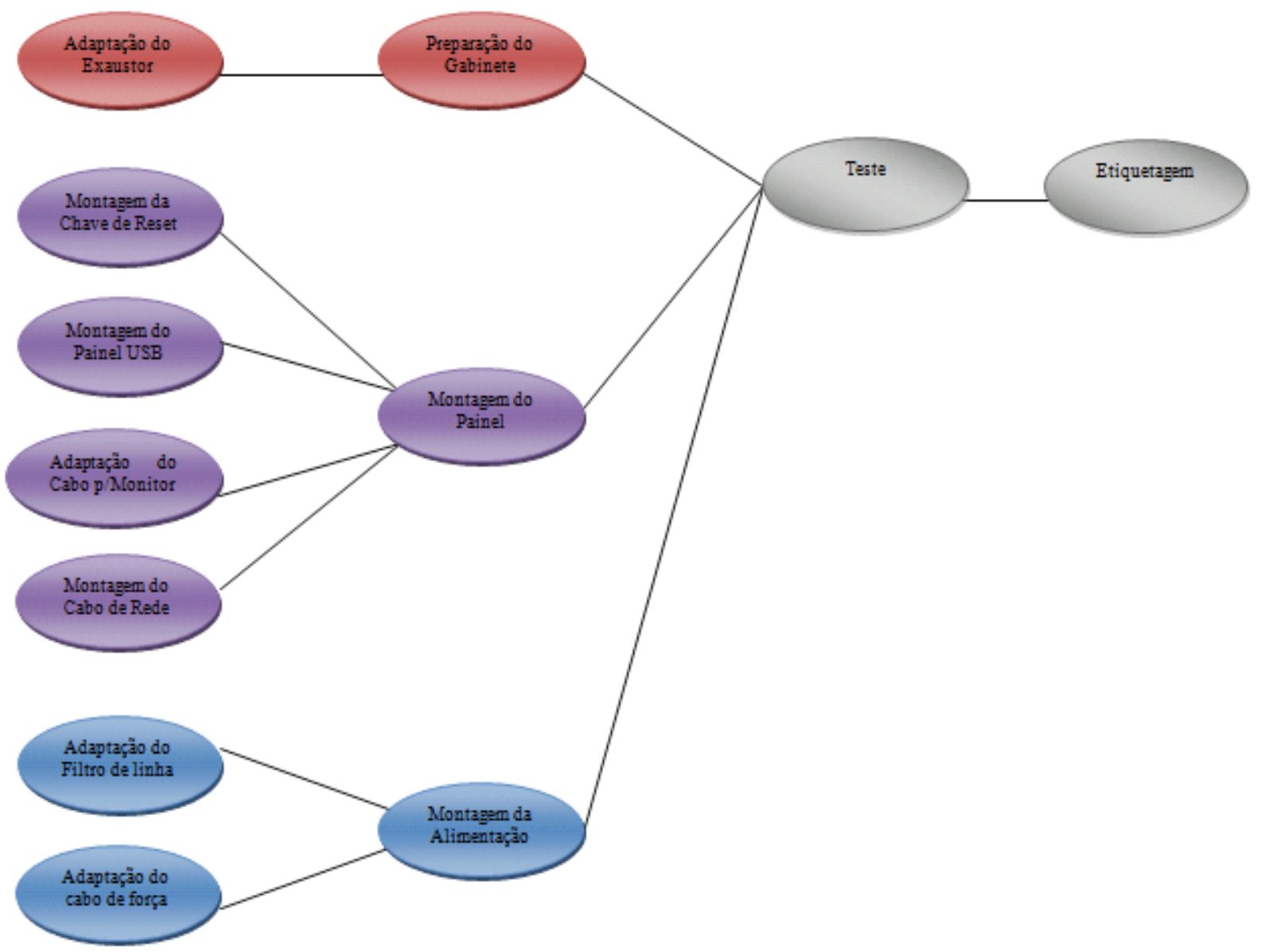

Figura 7 - Rede de processos do gabinete externo

De acordo com a figura 9, o posto de cor azul representa o local de programação dos micros controladores. O posto de cor branca representa as bancadas onde são realizadas as adaptações das fontes, montagem de placas e de cabos. A cor preta representa a mesa de montagem. A cor verde caracteriza as operações nos paletes e a cor cinza localiza a mesa de testes da qualidade.

Com estes dados levantados, é o momento da realização da quarta fase. O novo layout contou com a combinação de estantes com as mesas de montagem e com as bancadas, aproximando equipamentos com 
seus componentes específicos. As estantes foram estrategicamente distribuídas no setor e conterão materiais específicos para cada equipamento, agrupando componentes na formação de módulos dos equipamentos. Assim, serão evitadas misturas de matérias-primas com os produtos adaptados pela inclusão de mais estantes.

Tabela 5 - Processos do gabinete interno

\begin{tabular}{|c|l|c|l|}
\hline Cód & \multicolumn{1}{|c|}{ Processo } & Cód. & \multicolumn{2}{|c|}{ Processo } \\
\hline D1 & Gravação do Microcontrolador 89C51 & I6 & $\begin{array}{l}\text { Montagem do Cabo } \\
\text { Sincronismo }\end{array}$ \\
\hline D2 & Montagem da Placa SMTdp & I7 & $\begin{array}{l}\text { Furar Gabinete para Placa de } \\
\text { Sincronismo }\end{array}$ \\
\hline D3 & Montagem do Display LCD & I8 & $\begin{array}{l}\text { Instalação do Sistema Monitran no } \\
\text { HD }\end{array}$ \\
\hline D4 & Montagem do Cabo Serial & I9 & Montagem do Módulo de Informática \\
\hline D5 & Montagem do Cabo de Reset & A1 & Adaptação da Fonte para Detecção \\
\hline D6 & Montagem do Cabo de Alimentação & A2 & Adaptação da Fonte para Placa-Mãe \\
\hline D7 & Montagem da Chave de Manutenção & A3 & Montagem do Módulo de Alimentação \\
\hline D8 & Montagem do Módulo de Detecção & M0 & Montagem dos Módulos no Gabinete \\
\hline I1 & Gravação do Microcontrolador AT89C2 & G1 & Montagem do Cabo de Vídeo \\
\hline I2 & Gravação de Imagem no HD & G2 & Montagem do Exaustor \\
\hline I3 & Montagem da Placa de Sincronismo & G3 & Montagens no Gabinete \\
\hline I4 & Montagem do Cabo de Vídeo & G4 & Teste de Detecção \\
\hline I5 & Montagem do Cabo do Painel Frontal & G5 & Ajuste de Câmeras \\
\hline & & G6 & Etiquetagem \\
\hline
\end{tabular}

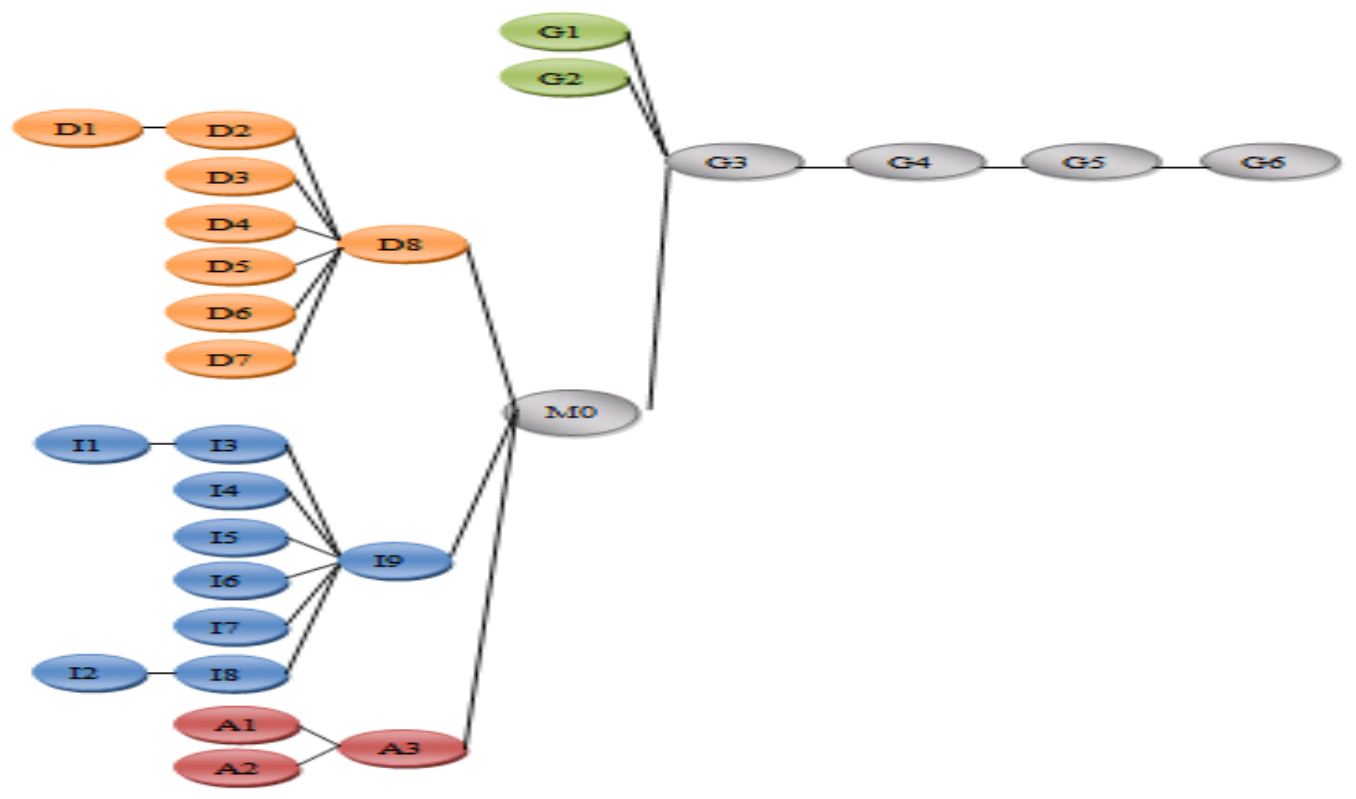

Figura 8 - Rede de processos do gabinete interno

De acordo com a Tabela 6, o layout proposto apresenta várias vantagens. 

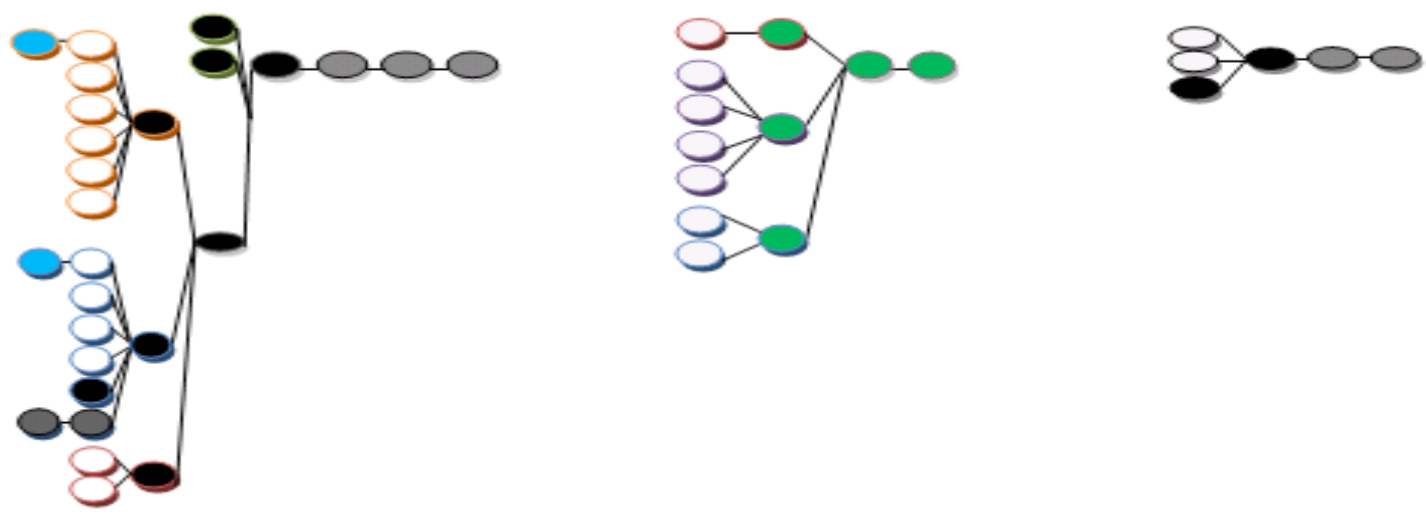

Figura 9 - Identificação dos postos

Tabela 6 - Indicadores de melhoria

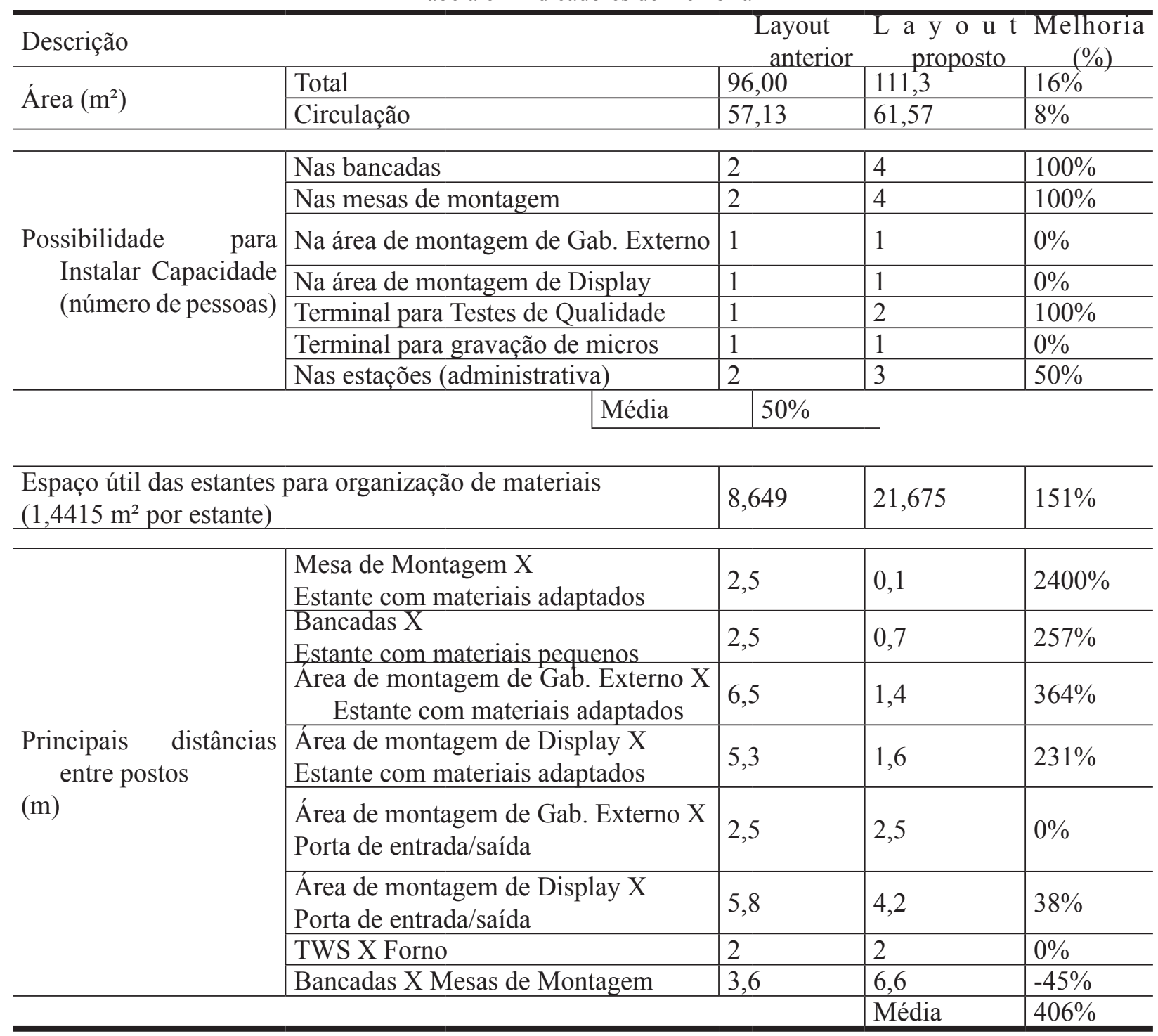

\subsubsection{Vantagens do novo modelo}

Neste novo arranjo foi possível reduzir ainda mais a distância média das estantes para as bancadas, 
passando de 2,5m para $0,7 \mathrm{~m}$ (redução de $72 \%$ ). As mesas de montagem foram dispostas de modo a reduzir por completo a distância com as estantes; ou seja, ficaram coladas. Através do rearranjo dos postos de trabalho e combinação de alguns objetos foi possível reduzir bastante as distâncias durante as diversas operações.

O layout final apresentou os seguintes benefícios:

- Área exclusiva de bancadas para montagem de placas, cabos e fontes. As estantes ficaram próximas e alinhadas contendo os materiais específicos para montagem das placas, cabos e fontes. Tornou-se fácil a visualização do estoque de matéria prima em processamento e acabados dessa área de bancadas;

- Corredor exclusivo para as mesas para montagem dos módulos dos equipamentos. Foi perceptível a facilidade no manuseio dos equipamentos (caixa de câmera, gabinete interno, SMTP e integrado) pela altura e apoio adequados proporcionados pelas mesas. Também foi possível uma maior organização dos materiais nas estantes, gerando uma melhor aparência. As estantes foram combinadas com as mesas de modo a tornar bastante ágil os movimentos durante as operações de montagem;

- Fluxo produtivo se tornou mais aparente, pois conta com dois extremos melhor definidos. Conta com fase de início (armazenamento intermediário para identificação) pela esquerda e fase final;

- Área de montagem de equipamentos mais pesados (gabinete externo e display) ficou próxima da porta de entrada/saída. Duas novas estantes foram alocadas ao lado dessa área com os materiais específicos para a montagem dos respectivos equipamentos;

- Uma nova estante foi disposta para armazenar e identificar os HDs gravados, assim como os micros controladores, as placas em desenvolvimento e placas SMD, facilitando o controle da área de programação;

- Área gerencial ficou disposta ao fundo do setor para não atrapalhar fluxo de produção. Um quadro branco foi adquirido para permitir a visualização e acompanhamento das ordens de fabricação do setor.

\section{CONCLUSÕES}

O presente artigo descreveu as mudanças de leiaute ocorridas dentro de uma empresa de tecnologia. Inicialmente, observou-se que o modelo de leiaute que estava sendo utilizado não fornecia a melhor movimentação dentro da planta. A segunda mudança se deu pois, com o surgimento da demanda de um novo item, a configuração celular não representava o melhor ganho para a organização

A mudança do arranjo físico celular para o arranjo físico funcional atingiu os objetivos, pois os itens fabricados, por possuírem processos com necessidades similares, foram localizados próximos um ao outro, beneficiando a utilização dos recursos materiais e transformadores.

O processo foi aplicado integralmente, sem necessidade de nenhuma adaptação. A mudança do arranjo físico foi bem aceita pelos funcionários por estarem dedicados a uma atividade específica integralmente, a cada etapa do processo. Assim, determinados tipos de layout não necessariamente melhores que outros, mas, dependendo de cada caso, um ou outro tipo pode ser mais indicado.

O novo arranjo apresentou vantagens características de um layout por processo:

- Adaptação de cada centro de trabalho com linha variada de componentes;

- Os produtos passam por centros de trabalho necessários formando uma rede de fluxos;

- Fácil percepção da falta de material localizada no sistema; 
Por tudo que foi exposto no presente artigo, pode-se constatar que não existe um tipo milagroso de leiaute, sendo necessário observar caso a caso para a escolha do formato mais adequado.

\section{REFERENNCIAS}

ALBERTIN, M. R. As Melhores Práticas de Gestão da Produção e Operações no Estado do Ceará. Fortaleza: Edições UFC, 2007.

BORBA, M.; BUA, C. P.; WELSH, M. N. A. Implantação de uma metodologia de layout em departamentos universitários. Anais ENEGEP, 2010 In: XXX ENCONTRO NACIONAL DE ENGENHARIA DE PRODUÇÃO. Editora ABEPRO: São Carlos: 2010.

BORGES, F. Q. Layout. Lato \& Sensu - Revista dos Monitores. v. 2, n. 4 UNAMA, Belém, 2001.

CHASE, R. B.; JACOBS, R. F.; AQUILANO, N. J. Operations management for competitive advantage with global cases. 11. ed. Editora New York McGraw - Hill, 2006.

CHIAVENATO, I. Administração de materiais: uma abordagem introdutória. São Paulo: Campus, 2005.

FREITAS, A. O.; OLAVE, M. E. L.; VIEIRA, R. K. Manufatura enxuta como ferramenta na mudança de layout do formato de "U" para o formato em "I". Um estudo de caso. In: XXVIII ENCONTRO NACIONAL DE ENGENHARIA DE PRODUÇÃO. Anais ENEGEP 2008. Editora ABEPRO: Rio de Janeiro 2008.

KRAJEWSKI, L., RITZMAN, L., MALHOTRA, M. Admisnistração de Produção e Operações. São Paulo: Pearson Prentice Hall, 2009.

LORENZATTO, J. T.; RIBEIRO, J. L. D. Projeto de layout alinhado às práticas de produção enxuta em uma empresa siderúrgica de grande porte. In: XXVII ENCONTRO NACIONAL DE ENGENHARIA DE PRODUÇÃO Anais ENEGEP 2007. Editora ABEPRO: Foz do Iguaçu, 2007.

MUTHER, R. Planejamento do Layout: Sistema SLP. São Paulo: Edgard Blücher, 1978.

NEUMANN, C. S. R.; MILANI, J. Proposição de melhoria do layout utilizando o SLP simplificado. In: XXIX Encontro Nacional de Engenharia de Produção. Anais ENEGEP 2009. Editora ABEPRO: Salvador, 2009.

PEINADO, J.; GRAEML, A. R. Administração da Produção : operações industriais e de serviços. Curitiba : UNICENP, 2007.

PRATA, A. B. Arranjo Físico Celular: Uma Abordagem Conceitual. (2002) Monografia (Curso de Especialização em Engenharia de Produção). Universidade Federal do Ceará. Fortaleza.

SILVA, A. L. e CARDOZA, E. Critical analysis of layout concepts: functional layot, cell leyout, product layout, modular layout, fractal layout, small factory layout. XVI International Conference on Industrial Engineering and Operations Management. Anais ICIEOM 2010. Editora ABEPRO: São Carlos, 2010.

SLACK, N.; CHAMBERS, S.; JOHNSTON, R. Administração da Produção. 2.ed. São Paulo: Atlas, 2002.

TUBINO, D. F. Planejamento e Controle da Produção - Teoria e Prática. São Paulo: Atlas, 2007. 


\title{
ELECTRONIC TECHNOLOGY COMPANY PROPER LAYOUT IDENTIFICATION
}

\begin{abstract}
Currently, there is a competitiveness imposed by globalized economy. It means that companies seek to produce better products with lower cost. Cost reduction can be gotten by production resources location optimization, representing a competitive advantage for businesses, by reducing handling costs in production system. This paper aims to study and make a layout change in electronic technology company. It was decided to work with two different layouts: functional and celular. The functional layout was chosen. The functional layout was defined the best one in this case because there are processes with the same necessities and were located near each other, benefiting the resources utilization.
\end{abstract}

Keywords: Layout models. Competitiveness. Transportation Time Reduction. 